\title{
A simple and efficient transient transformation for hybrid aspen (Populus tremula $\times P$. tremuloides)
}

\author{
Naoki Takata ${ }^{1,2}$ and Maria E Eriksson ${ }^{1,3^{*}}$
}

\begin{abstract}
Background: The genus Populus is accepted as a model system for molecular tree biology. To investigate gene functions in Populus spp. trees, generating stable transgenic lines is the common technique for functional genetic studies. However, a limited number of genes have been targeted due to the lengthy transgenic process. Transient transformation assays complementing stable transformation have significant advantages for rapid in vivo assessment of gene function. The aim of this study is to develop a simple and efficient transient transformation for hybrid aspen and to provide its potential applications for functional genomic approaches.

Results: We developed an in planta transient transformation assay for young hybrid aspen cuttings using Agrobacterium-mediated vacuum infiltration. The transformation conditions such as the infiltration medium, the presence of a surfactant, the phase of bacterial growth and bacterial density were optimized to achieve a higher transformation efficiency in young aspen leaves. The Agrobacterium infiltration assay successfully transformed various cell types in leaf tissues. Intracellular localization of four aspen genes was confirmed in homologous Populus spp. using fusion constructs with the green fluorescent protein. Protein-protein interaction was detected in transiently co-transformed cells with bimolecular fluorescence complementation technique. In vivo promoter activity was monitored over a few days in aspen cuttings that were transformed with luciferase reporter gene driven by a circadian clock promoter.

Conclusions: The Agrobacterium infiltration assay developed here is a simple and enhanced throughput method that requires minimum handling and short transgenic process. This method will facilitate functional analyses of Populus genes in a homologous plant system.
\end{abstract}

Keywords: Populus, Agrobacterium-mediated vacuum infiltration, Transient expression, Subcellular localization, Co-localization, Luciferase reporter assay

\section{Background}

The genus Populus, which includes poplar, aspen, and cottonwood species, can serve as a model organism for perennial woody plants. Populus trees have several potential biological advantages such as small genome size, over 30 species growing worldwide, rapid juvenile growth, ease of clonal propagation, simplicity of genetic transformation and regeneration, and extensive genetic maps. The first draft genome of black cottonwood (Populus trichocarpa) was published in 2006 [1] and

\footnotetext{
* Correspondence: maria.eriksson@plantphys.umu.se

'Umeå Plant Science Centre, Department of Plant Physiology, Umeå

University, SE-901 87, Umeå, Sweden

${ }^{3}$ Department of Plant Sciences, University of Cambridge, Cambridge CB2 3EA, UK

Full list of author information is available at the end of the article
}

provided the first insights into the genomic organization of a tree species. The genome contains more than 45,000 protein-coding genes and $\sim 12 \%$ of the genes show no similarity to genes in the model plant Arabidopsis thaliana [2]. To unravel the biological function of Populus genes, transgenic trees are generated and characterized, providing insight in unique characteristics, life style, and biological organization of perennial woody plants. However, a limited number of Populus genes have been targeted in transgenic studies due to a lengthy transformation process and the need for characterization of many transgenic lines for each construct.

Transient transformation assays complement stable transformation and make gene function analysis more efficient. Transient gene expression techniques (e.g., biolistic bombardment, protoplast transfection, and Agrobacterium

\section{Biomed Central}


tumefaciens (Agrobacterium)-infiltration) are available for model plants such as Arabidopsis and rice as well as for crop plants such as corn, potato, soybean, tomato, and wheat [3-7]. In Populus spp., several studies have successfully demonstrated transient gene expression via biolistic bombardment, protoplast transfection, and Agrobacterium co-cultivation [8-13]. For example, leaf epidermal and guard cells were transiently transformed with a reporter construct in a hybrid poplar (Populus tremula $\times$ Populus alba) by particle bombardment [12]. Transient transfection of Populus protoplasts isolated from leaf tissues and suspension culture cells was achieved either by means of electroporation or chemically with polyethylene glycol $[8,10,12]$. Agrobacterium co-cultivation was used to examine ectopic expression of a reporter gene in $P$. nigra, $P$. tomentosa, and P. trichocarpa before the regeneration of stable transformants $[9,11,13]$. However, such transformation assays have certain disadvantages such as the requirement for expensive equipment and supplies associated with particle bombardment. In addition, the transformation efficiency is relatively low in the transfection of Populus protoplasts, and only a small piece of a tissue isolated from seedlings is used in Agrobacterium co-cultivation. To avoid these drawbacks, another transient assay such as Agrobacterium-mediated infiltration would be useful for Populus trees. This assay allows for a simple transformation process, easy operation, and high transformation efficiency in several plant species including Arabidopsis, grapevine, potato, switchgrass, tobacco, and tomato [6,7,14-17].

Transient transformation techniques are available for rapid in vivo analyses of gene function such as protein subcellular localization, protein-protein interaction, and promoter activity. For in vivo functional analyses, reporter genes such as green fluorescence protein (GFP), variants of GFP, and firefly luciferase (LUC) are common tools for molecular and cell biology studies. Protein subcellular localization, which is crucial for elucidating the cellular functions of proteins, is easily monitored by a transient expression of fluorescent fusion protein [18]. In this assay, a reporter construct harboring the gene of interest is fused with GFP or its variants and is transiently transformed into plant cells where intracellular localization is visualized through fluorescence of the reporter gene. Fluorescent proteins are also used for in vivo protein-protein interactions. Interaction assays, such as bimolecular fluorescence complementation (BiFC) and fluorescence resonance energy transfer (FRET), allow visualization of protein-protein interaction and subcellular localization of target proteins [19]. In these assays, transient co-transformation techniques with two different constructs are a convenient and practical alternative to generation of double-transformed transgenic plant and allow testing of several constructs and combinations. In addition to fluorescent proteins, LUC is used as a reporter gene mainly for measuring transcriptional activity. The LUC reporter is suitable for real-time monitoring of gene expression as it has a relatively short half-life compared to fluorescent proteins. For example, expression patterns of circadian clockrelated genes, most of which show rhythmic expression in a day, are extensively examined by LUC reporter assays [20]. Typically, these assays use bioluminescence to visualize diurnal or circadian rhythms that express the LUC gene driven by a clock promoter of transgenic plants. Although studies regarding the plant clock system have principally been conducted using stable transformants, published studies report successful transient LUC assays [21,22].

In this study, we develop a transient transformation assay- Agrobacterium-mediated vacuum infiltration-for a model tree, hybrid aspen (P. tremula $\times P$. tremuloides). The assay was optimized for aspen leaves and applicable to various cell types in leaf tissue. We investigated subcellular localization of Populus proteins and protein interaction by co-transformation of two different plasmids in aspen leaf cells. Furthermore, in vivo promoter activity of a hybrid aspen clock gene was measured using a LUC reporter assay. The transient transformation assay we developed is enhanced throughput and easily employed for rapid functional analyses of Populus gene and protein expression.

\section{Results and Discussion}

\section{Transient transformation in hybrid aspen cuttings}

We first examined whether the syringe injection technique, used in tobacco species, was useful for hybrid aspen leaves [14]. An infiltration medium [10 mM $\mathrm{MgCl}_{2}$ and $5 \mathrm{mM}$ MES-KOH (pH 5.6)] in a blunt-tipped plastic syringe was forced into an abaxial epidermis of full-expanded aspen leaves that grew in soil for one month. The medium was permeated around the syringe contact area but limited to the wider area due to a leaf vein network (Additional file 1). Next, we investigated whether Agrobacterium-mediated vacuum infiltration increased the permeability of an infiltration medium for hybrid aspen leaves. Vacuum infiltration for transient gene expression has been systematic used in various plants such as Arabidopsis, citrus, lentil, switchgrass, and sunflower [15,17,23-25]. Briefly, hybrid aspen cuttings grown in the aseptic agar medium were submerged in an Agrobacterium solution with or without 0.003\% Silwet L-77 and then vacuum-infiltrated. The infiltration solution penetrated throughout the aspen leaves by the aid of a low-pressure vacuum and the detergent (see below). Thus we could develop an Agrobacterium infiltration technique mediated by vacuum in aspen cuttings. 
Transient transformation was monitored by the expression binary vector pPZP221-CaMV35S::EmGFP in the A. tumefaciens strain GV3101 (pMP90). Agrobacterium cells grown until stationary phase were resuspended in an infiltration medium. Vacuum infiltration was performed using three- to four-week-old aspen cuttings without removing any tissues. When using a shoot detached from root tissues, the infiltration medium could not be evaporated from the intercellular spaces of the leaves and few cells were successfully transformed (data not shown). After three days of the transformation, GFP signals were principally observed in younger leaves and scattered in individual cells (Figure 1A-F). Most of the transformed cells were in the middle to tip region of the leaves. Although the intact plants were submerged and vacuum-infiltrated in the bacterial solution, few cells had GFP signals in petioles, stipules, stems, and roots (data not shown). GFP fluorescence was detected in various cell types such as epidermal cells, guard cells, and mesophyll cells in the leaf tissues (Figure 1G-O). This result indicates that the Agrobacterium-mediated vacuum infiltration technique can be used to analyze cells in young leaves. The validity of the tissue-dependent transformation is also described in Agrobacterium-mediated infiltration assay of Arabidopsis, where young cotyledons are more highly transformed than petioles and roots [15]. In the following studies, we principally used younger leaves for monitoring transformed cells.

\section{Conditions for efficient transient transformation in hybrid aspen leaves}

We optimized the transformation conditions such as the infiltration medium, the concentration of Silwet L-77, the growth phase of bacteria, and the density of bacteria. Studies using other plant species report that these conditions influence the transient transformation efficiency in Agrobacterium infiltration technique [7,15,17,25,26]. We first estimated the effect of an infiltration medium on transformation efficiency. Two media were tested: (i) $10 \mathrm{mM} \mathrm{MgCl} 2$ and $5 \mathrm{mM}$ MES-KOH (pH 5.6) established in an Agrobacterium-mediated vacuum infiltration of Arabidopsis [15] and (ii) $0.5 \times \mathrm{MS}$ medium and $5 \mathrm{mM}$ MES-KOH ( $\mathrm{pH} 5.6$ ) based on the culture medium of hybrid aspen. A saturated overnight culture of Agrobacterium was re-suspended in the media containing $200 \mu \mathrm{M}$ Acetosyringon and then diluted to a final $\mathrm{OD}_{600}$ of 0.5 . Next, $0.0075 \%$ Silwet L-77 was added to the solution before applying vacuum. Three days after the vacuum-infiltration, GFP positive cells in the younger leaves were

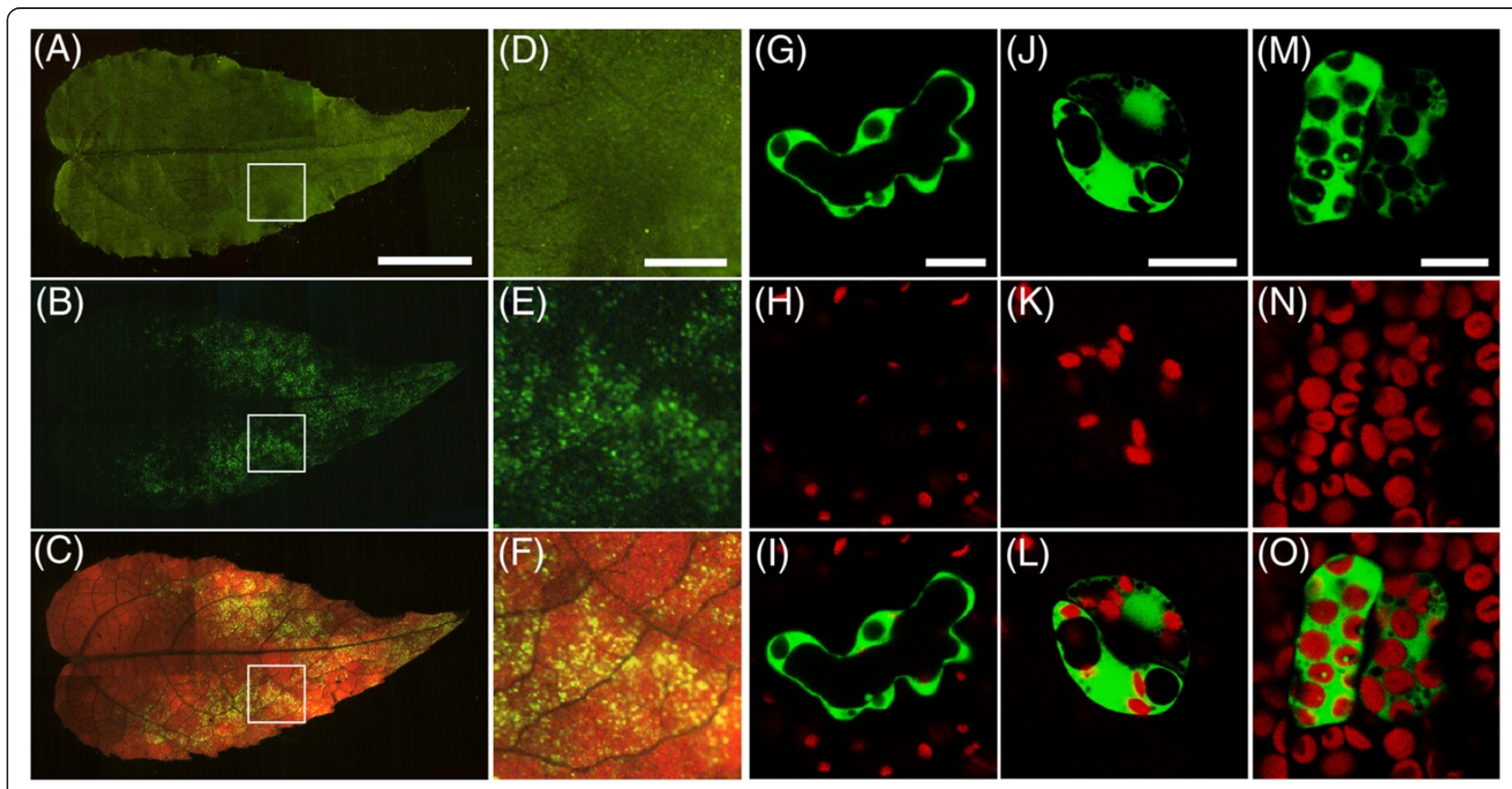

Figure 1 Expression of GFP in hybrid aspen using Agrobacterium-mediated vacuum infiltration. (A-F) Transient expression of GFP in aspen leaves. CaMV35S::EmGFP construct was transformed into hybrid aspen cuttings. Bright field image (A and $\mathbf{D})$, GFP fluorescence (B and $\mathbf{E})$, and GFP fluorescence and chloroplast autofluorescence ( $\mathbf{C}$ and $\mathbf{F})$ were captured using a fluorescence stereomicroscope. Scale bar $=5 \mathrm{~mm}(\mathbf{A}-\mathbf{C})$. Areas with a white box in $\mathbf{A}, \mathbf{B}$, and $\mathbf{C}$ are magnified in $\mathbf{D}, \mathbf{E}$, and $\mathbf{F}$, respectively. Scale bar $=1 \mathrm{~mm}$ (D-F). (G-O) Transient expression of GFP in various cell types in aspen leaves. GFP signals were observed in epidermal cells (G-I), guard cells (J-L), and mesophyll cells (M-O). GFP

fluorescence (G, J, and $\mathbf{M})$ and autofluorescence of chloroplasts $(\mathbf{H}, \mathbf{K}$, and $\mathbf{N}$ ) were captured using a CLSM. GFP signal and autofluorescence of chloroplasts were merged (I, $\mathbf{L}$, and $\mathbf{O})$. Scale bar $=10 \mu \mathrm{m}$. 
scanned and counted in small compartments $\left(1.5-\mathrm{mm}^{2}\right.$ leaf area) to evaluate the transformation efficiency. The leaves transformed in the MS solution possessed $14.6 \pm 1.2$ (average \pm SE) GFP positive cells per compartment (Figure 2A). However, fewer cells were transformed in the magnesium chloride solution $(5.4 \pm 0.6$ cells per compartment). Hence, we decided to use the MS medium for further estimations of transient transformation.

Next, we investigated the effect of the surfactant Silwet L-77 concentration on the transient transformation efficiency. The presence of the surfactant allows a bacterial solution to penetrate into leaf lumen and boost the transient transformation efficiency, although excess surfactant accelerated necrosis of Arabidopsis leaf cells [26]. In this study, Silwet L-77 (0\%, 0.003\%, 0.0075\%, 0.015\%, and $0.03 \%$ ) was added to the infiltration solution in which the bacteria were suspended $\left(\mathrm{OD}_{600}=0.5\right)$ before the vacuum infiltration. As expected, few cells showed GFP fluorescence following transformation with media lacking Silwet L-77 because the penetration of the solution to the leaves was limited (Figure 2B). The Silwet L77 concentration was positively correlated with the transformation efficiency and the highest number of transformed cells was obtained with $0.015 \%$ Silwet L-77 in the solution. However, in the medium containing
0.03\% Silwet L-77, leaf cells appeared to be feeble and to be less transformed (data not shown). In the Arabidopsis transient transformation by co-cultivation with Agrobacterium, a similar positive correlation between the transformation efficiency and the Silwet L-77 concentration are reported and peak efficiency was established at $0.005 \%$ of Agrobacterium solution [26]. In this study, the surfactant concentration for aspen cuttings was three times higher than in Arabidopsis; this difference was probably because of different leaf structures and ages between species. In addition, transformation procedures were distinct from each other. We fixed the concentration at $0.015 \%$ of the Agrobacterium solution for aspen plants.

We determined the bacterial growth stage and density in the infiltration medium. The appropriate bacterial conditions lead to higher transformation rate in various plants, although the conditions depend on plant species $[7,15,16,23,24,26]$. To determine the appropriate bacterial growth stage, we harvested Agrobacterium at two growth phases-the $\log \left(\mathrm{OD}_{600}=0.8\right)$ and the stationary $\left(\mathrm{OD}_{600}=1.6\right)$. The bacteria were re-suspended in the MS medium to an $\mathrm{OD}_{600}$ of 0.5 . The leaf cells were successfully transformed in the stationary phase bacteria (data not shown). However, few transformed cells were obtained in the log phase bacteria, although an
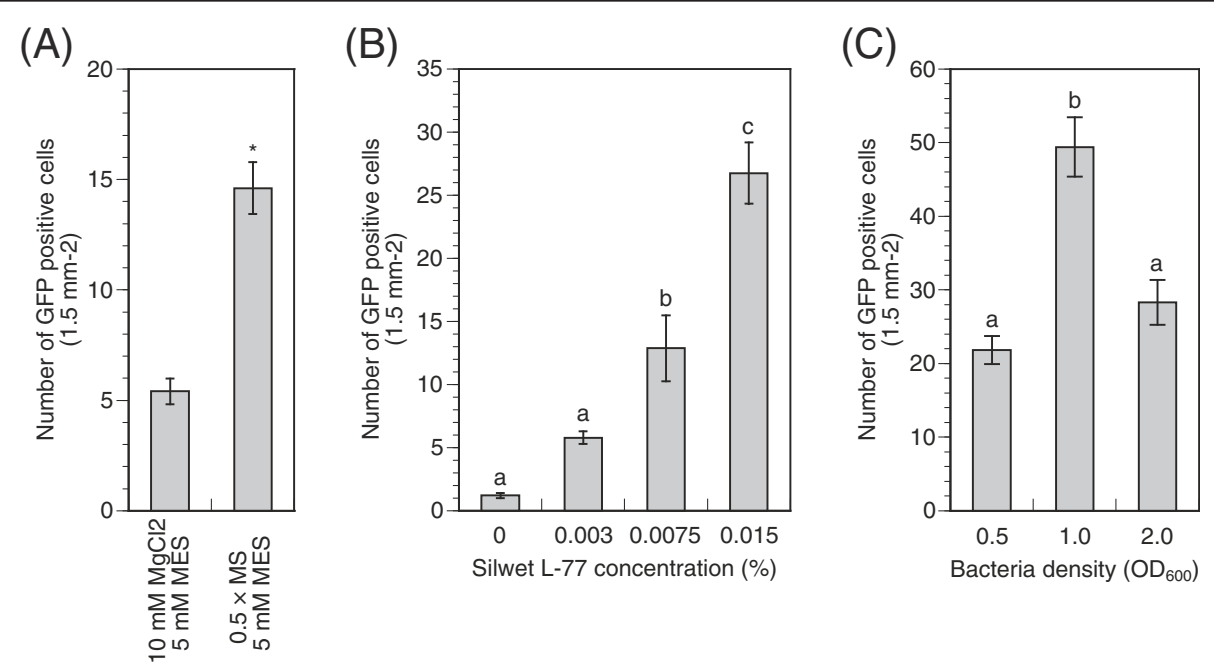

Figure 2 Transient transformation efficiency in hybrid aspen leaves. (A) Effect of infiltration medium on transient transformation. Overnight culture of Agrobacterium was re-suspended in individual infiltration medium containing $200 \mu \mathrm{M}$ Acetosyringon and $0.0075 \%$ Silwet L-77 (final $\mathrm{OD}_{600}=0.5$ ). The GFP signals were observed after three days of the transformation. Transformation efficiency was calculated by counting GFP positive cells in a $1.5-\mathrm{mm}^{2}$ leaf area. Values are means $\pm S E(n=330)$. Asterisk indicates a statistically significant difference based on a Student's $t$ test $(\mathrm{P}<0.01)$. (B) Effect of Silwet L-77 concentration on transient transformation. Overnight culture of Agrobacterium was re-suspended in the medium [0.5 $\times$ MS, 5 mM MES-KOH (pH 5.6) and $200 \mu \mathrm{M}$ Acetosyringon] (final $\mathrm{OD}_{600}=0.5$ ). Appropriate Silwet L-77 was added to the solution. Values are means $\pm S E(n=350)$. Means with different letters are different according to Tukey's HSD test $(P<0.05)$. (C) Effect of bacteria density on transient transformation. Overnight culture of Agrobacterium was re-suspended in the medium $[0.5 \times \mathrm{MS}, 5 \mathrm{mM} \mathrm{MES}-\mathrm{KOH}(\mathrm{pH} 5.6), 200 \mu \mathrm{M}$ Acetosyringon and $0.015 \%$ Silwet L-77]. The final $\mathrm{OD}_{600}$ was adjusted to $0.5,1.0$, and 2.0. Values are means $\pm S E(n=480)$. Means with different letters are different according to Tukey's HSD test $(P<0.05)$. The experiments shown are from two or three experiments each of which included three biological repeats. For each biological repeat, 40 to 60 sectors were measured. 
Agrobacterium at log phase growth was harvested and used to generate a stable transformant of hybrid aspen [27]. Next, we investigated the bacterial densities in the infiltration medium using the bacteria at the stationary phase growth. The final $\mathrm{OD}_{600}$ in the infiltration medium was adjusted to $0.5,1.0$, and 2.0. The highest transformation efficiency was achieved with a final bacterial density of $\mathrm{OD}_{600}=1.0$ (Figure 2C). When in the higher $\left(\mathrm{OD}_{600}=2.0\right)$ and lower $\left(\mathrm{OD}_{600}=0.5\right)$ bacterial concentration, the transformation yield dropped by half. Altogether, the simple and efficient transient transformation assay (the Agrobacterium-mediated vacuum infiltration) was optimized and developed for younger leaves of hybrid aspen, which were showing a higher incidence of transformation compared to older tissues.

\section{Subcellular localization of aspen proteins}

One of the major applications of transient transformation assays is to observe the subcellular localization patterns of proteins in cells. Several studies have applied transient transformation to monitor subcellular localization of Populus proteins in heterologous plant systems [28-31]. However, few localization studies were tested in homologous Populus spp. Thus, we examined subcellular localization of Populus proteins in a homologous plant system using an Agrobacterium-mediated vacuum infiltration.

This study examined the intracellular localization of four aspen genes-CINNAMIC ACID 4-HYDROXYLASE (C4H), GLYCOSYLTRANSFERASE FAMILY 47 (GT47C), METAL-TOLERANCE PROTEIN 1 (MTP1) and PEROXIREDOXIN Q (PrXQ)- which were previously described in heterologous plant expression system [28,29,32,33]. The expression vectors of C-terminal GFP tagged proteins were transiently transformed into hybrid aspen cuttings using Agrobacterium-mediated vacuum infiltration. We first determined the subcellular localization of the PttMTP1-EmGFP fusion proteins. The PttMTP1 protein, a vacuolar zinc transporter [28], was localized to the ring-like structure of the vacuolar membrane (Figure 3A). The tonoplast localization of the protein was distinguishable from the plasma membrane marked by lipophilic styryl dye FM4-64. The GFP signals of the PttPrxQ-EmGFP proteins overlapped with the autofluorescence of plastids (Figure 3B), in accordance with the finding that PrxQ is involved in detoxifying peroxides at the thylakoid membrane [29]. The PttC4H, a member of the cytochrome P450 monooxygenase superfamily, was distributed in the reticular network of ER labeled with ER Tracker (Figure $3 \mathrm{C}$ ). The $\mathrm{C} 4 \mathrm{H}$ protein targets ER in Arabidopsis and tobacco cells [32,34]. Finally, we tested the intracellular localization of the PttGT47C-EmGFP. The fluorescence from GFP-tagged PttGT47C exhibited a punctate pattern in the cytoplasm and was co- localized with the Golgi marker dye BODYPY TR ceramide (Figure 3D). In previous studies, Arabidopsis GT47C (FRA8) and poplar GT47C exhibited a similar localization pattern and served as a Golgi marker $[33,35,36]$. Therefore, the transient transformation protocol results showed reliability with respect to subcellular localization of the proteins selected to test targeting to various cell compartments.

\section{Co-transformation and protein-protein interaction by BiFC assay}

We next investigated whether the transformation technique could be applicable to transient co-transformation assay in aspen leaves. To this end, we tested the BiFC assay, which is a powerful tool for visualizing proteinprotein interactions in living cells. The transient BiFC assay is often performed via Agrobacterium infiltration technique in tobacco and Arabidopsis [15,26,37]. In this study, the validity of transient BiFC assay was evaluated using the Arabidopsis CYCLIN D3;1 (CYCD3;1) and RETINOBLASTOMA-RELATED 1 (RBR1) proteins for which an interaction has been shown in the nucleus [[38], Bakó László, personal communications]. A set of binary vectors for the BiFC assay-pGreen-CaMV35S:: cEYFP-AtCYCD3;1 and pGreen-CaMV35S::nEYFP-AtRB R1-was transiently infiltrated into aspen cuttings. The EYFP fluorescence was detected in the nucleus colocalized with DAPI staining (Figure 3E), suggesting that AtCYCD3 and AtRBR1 formed a protein complex and functioned in the nucleus. However, co-transformation efficiency appeared to be lower than transformation with a single construct. This result suggests that two different constructs are successfully introduced into a single cell of hybrid aspen leaves and are viable for detecting protein interactions via BiFC using the Agrobacteriumvacuum infiltration technique.

\section{LUC reporter assay using Populus circadian clock gene promoter}

Finally, we tested whether the transient transformation technique can be used in combination with the LUC reporter. We focused on rhythmic expression pattern of a circadian clock gene. Many circadian clock-related genes are identified in the model plant Arabidopsis and most of them show diurnal and circadian expression patterns in a phase-dependent manner [39]. The LUC reporter system easily and precisely estimates the rhythmic expression of a clock-related gene since gene expression can be followed as the LUC activity in the same plant over several days [20]. As the reporter system is generally applicable for a plant that stably expresses the LUC gene, a few studies have tested the possibility of the system using transient transformation assay [21,22]. 
We targeted the promoter of Populus LATE ELOGATED HYPOCOTYL 2 (LHY2) gene, a key factor in the plant circadian clock system [40,41], in the transient LUC reporter assay. The reporter construct (PttLHY2promoter::luc ${ }^{+}$) was transformed into hybrid aspen seedlings by the Agrobacterium-mediated vacuum infiltration. The LUC activities were detected at one-hour intervals under light/dark cycles for two days. The $L U C$ expression was robust in the shoot tips and the younger leaves (Additional file 2). In the leaves, the LUC activities in the young folded leaves were higher than those in the expanding and expanded leaves. The bioluminescence reflecting the PttLHY2 gene expression showed a diurnal rhythm and a peak of the rhythm occurred 1-2 hours after dawn (Figure 4). The typical diurnal expression in the transformed aspen apices was followed over two days, although the luminescence level was reduced on the second day. A similar diurnal rhythm of Populus LHY2 gene has been reported in the previous studies; these studies examined the expression level using the Real-time PCR technique [40,41]. Compared with the diurnal rhythm determined by Real-time PCR, more acute peaks in $L H Y 2$ expression were monitored in the transient LUC assay, indicating that the assay would be a good tool for evaluating the phase and period of circadian expression. Taken together, the Agrobacterium-infiltration technique and the LUC reporter assay could be used to analyze driven, diurnal gene expression and could accelerate functional analysis of Populus clock-related genes.

\section{Conclusions}

We have developed a novel transient transformation assay for hybrid aspen cuttings. For the Populus species, 


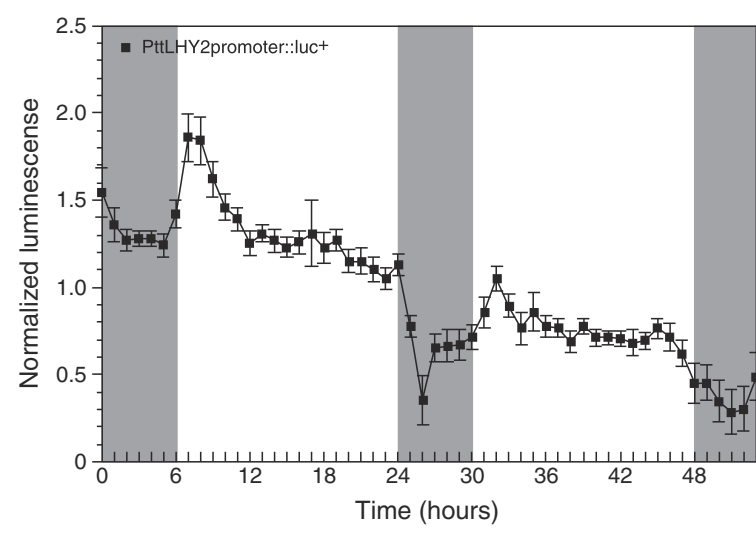

Figure 4 LUC reporter assay in hybrid aspen apices. The plasmid construct containing PttLHY2promoter:.:luc ${ }^{+}$was transformed into aspen cuttings using the Agrobacterium-mediated vacuum infiltration assay. The apices were supplemented with luciferin solution at one day after the transformation. The LUC activity was detected by a cooled CCD camera beginning about $5 \mathrm{~h}$ following addition of substrate to obtain dynamic, real-time expression. Gray and white boxes indicate subjective night and day, respectively. Luminescence values are means \pm SE (biological replicates $n=5$ ).

this simple assay has a higher throughput than the conventional transient assays [12]. Furthermore, this assay could be used to conduct quick functional analysis of protein subcellular localization, protein-protein interaction, and in vivo promoter activity. Although this technique is optimized in a wild-type plant, it can be applied to stable transgenic aspens, enabling the generation of a double mutant without additional long-term transformation process. Consequently, the transient transformation assay will facilitate functional analyses of Populus genes from various genera in a homologous plant system.

\section{Methods}

\section{Plant material}

Sterile rooted cuttings of hybrid aspen $P$. tremula $\times$ P. tremuloides (Ptt; wild type clone T89) were used for transient transformation assay. The cuttings were grown in $0.5 \times$ Murashige and Skoog (MS) medium ( $\mathrm{pH}$ 5.6) containing $0.8 \%(\mathrm{w} / \mathrm{v})$ agar under a cycle of $18 \mathrm{~h}$ fluorescent light $(50 \mu \mathrm{mol} \mathrm{m}-2 \mathrm{~s}-1) / 6 \mathrm{~h}$ dark; $22^{\circ} \mathrm{C} / 18^{\circ} \mathrm{C}$.

\section{GFP-based constructs}

The pUC18-based expression vector that harbors EmGFP gene (Invitrogen, USA) driven by the Cauliflower Mosaic Virus 35S (CaMV35S) promoter was provided by Dr. Tomokazu Yamazaki (Graduate School of Life Sciences, Tohoku University) [42,43]. The cloning sites (XbaI and BamHI) between the CaMV35S promoter and EmGFP were altered into unique restriction sites (SpeI and KpnI) by PCR-based site-directed mutagenesis [44] using the following primer set: forward,
5'TACAGTCGACACTAGTGGTACCATGGTGAG-3'; and reverse, 5'-CTCACCATGGTACCACTAGTGTCGA CTGTA-3'. To create a binary vector harboring CaMV35S:: EmGFP, the pUC18-based vector was digested with EcoRI and HindIII and subsequently introduced into the EcoRI/ HindIII site of the binary vector pPZP221 [45].

cDNA clones of C4H, GT47C, MTP1 and PrxQ were isolated from $P$. tremula $\times P$. tremuloides $\mathrm{cDNA}$ libraries [46]. Accession numbers of PttC4H, PttGT47C, PttMTP1, and PttPrxQ are BU883009, AI162472, BU893269, and BU813259, respectively. Coding sequence of these genes (without stop codon) were amplified by PCR using Platinum $p f x$ DNA polymerase (Invitrogen, USA) with following primer sets: PttC4H (forward, 5'-CACCACTAGTATGGATCTCCTCCTCCT GG-3'; reverse, 5'-GGTACCAAAGGACCTTGGCTTT GCAAC-3'), PttGT47C (forward, 5'-CACCACTAGTAT GAAACTATTACACAGACATGCT-3'; reverse, 5'-GGT ACCGTGGTTTGAAAGCCTCACG-3'), PttMTP1 (forward, 5'-CACCACTAGTATGGAAGCACAAAATCCT CAG-3'; reverse, 5'-GGTACCACGCTCTATCTGGAT GGTTAC-3') and PttPrxQ (forward, 5'-CACCACTAG TATGGCTTCCATTTCTCTCCC-3'; reverse, 5'-GGT ACCAAGGCTTTGAAGTAGTTTAAGAGTT-3'). The PCR products were digested with SpeI and KpnI and subsequently introduced into the SpeI/KpnI site between the CaMV $35 \mathrm{~S}$ promoter and EmGFP of the expression binary vector pPZP221-CaMV35S::EmGFP.

\section{Agrobacterium infiltration}

The expression binary vectors were transformed into Agrobacterium tumefaciens strain GV3101 (pMP90) [47]. Agrobacterium harboring individual vector was inoculated in LB media with appropriate antibiotics. An overnight culture of Agrobacterium was harvested at $\mathrm{OD}_{600}$ of 0.8 or 1.6 , centrifuged at $4,000 \times \mathrm{g}$ for $20 \mathrm{~min}-$ utes, and re-suspended in $25 \mathrm{~mL}$ of infiltration medium. This step was repeated. Finally, Agrobacterium cells were suspended in $100 \mathrm{~mL}$ of infiltration medium. Two infiltration media were used in this study: (i) $10 \mathrm{mM} \mathrm{MgCl}$, $5 \mathrm{mM}$ MES- $\mathrm{KOH}$ ( $\mathrm{pH} 5.6$ ), and $200 \mu \mathrm{M}$ Acetosyringon and (ii) $0.5 \times \mathrm{MS}$ medium, $5 \mathrm{mM}$ MES-KOH ( $\mathrm{pH} 5.6$ ), and $200 \mu \mathrm{M}$ Acetosyringon at $\mathrm{OD}_{600}$ of $0.5,1.0$, or 2.0. The bacterial solution was incubated at room temperature for three hours with gentle shaking under dark conditions. Hybrid aspen T89 cuttings (three to four week-old) were soaked in Agrobacterium solution containing $0 \%, 0.003 \%, 0.0075 \%, 0.015 \%$, or $0.03 \%$ concentrations of Silwet L-77 (Lehle Seeds, USA) and then Agrobacterium infiltration was performed by applying vacuum (Boekel Scientific, USA) three times for three minutes. The aspen cuttings were subsequently put on paper towels to remove excess infiltration medium and transplanted in $0.5 \times \mathrm{MS}$ medium $(\mathrm{pH} 5.6)$ with $0.6 \%$ 
(w/v) agar and $50 \mu \mathrm{g} / \mathrm{mL}$ Cefotaxime. The cuttings were returned to grow under initial growing conditions for three days before imaging.

\section{Microscopy}

Images of whole leaves were monitored by a fluorescence stereomicroscope (Leica MZ FLII, Germany) with a GFP3 filter (excitation 470/40, emission 525/50 nm) (Leica, Germany) for GFP fluorescence and a GFP2 filter (excitation 480/40 nm, emission $510 \mathrm{~nm}$ ) (Leica, Germany) for GFP fluorescence and chloroplast autofluorescence. For the evaluation of transformation efficiency, GFP images in a $1.5-\mathrm{mm}^{2}$ leaf area were captured using an epifluorescence microscopy (Axioplan 2 imaging, Carl Zeiss, Germany) with Zeiss filter set 09 (excitation 450$490 \mathrm{~nm}$, emission $510 \mathrm{~nm}$ ) (Carl Zeiss, Germany). GFP positive cells were counted in the small compartments using ImageJ 1.44 software [48].

\section{Staining and confocal microscopy}

For confocal laser scanning microscopy (CLSM), GFP fluorescence, chloroplast autofluorescence and fluorescence of organelle markers in transformed cells were monitored using a Leica TCS SP2 AOBS system (Leica, Germany) with a water-corrected $63 \mathrm{x}$ objective NA $=1.2$ (HCX PL APO 63.0x1.20 W BD UV, Leica, Germany) and a Leica TCS SPE system (Leica, Germany) with an oil-corrected 63x objective NA $=1.3$ (ACS APO 63.0x1.30 OIL CS, Leica, Germany). For subcellular localization, transformed leaves were stained with plasma membrane marker FM4-64 $(32 \mu \mathrm{M}$, Invitrogen, USA), ER marker ER-Tracker Blue-White DPX $(1 \mu \mathrm{M}$, Invitrogen, USA) or Golgi marker BODIPY TR ceramide (5 $\mu \mathrm{M}$, Invitrogen, USA). GFP and chlorophyll were excited at $488 \mathrm{~nm}$ laser. GFP and Chlorophyll emission were detected between 500 to $550 \mathrm{~nm}$ and between 664 to 696 nm, respectively. FM4-64 and BODIPY TR ceramide were excited at $532 \mathrm{~nm}$ laser. Fluorescence of FM4-64 and BODIPY dye were monitored between 640 to $660 \mathrm{~nm}$ and between 610 to $630 \mathrm{~nm}$, respectively. ER-Tracker BlueWhite DPX was excited at $405 \mathrm{~nm}$ laser and the emission was detected between 430 to $460 \mathrm{~nm}$.

\section{BiFC assay}

The BiFC vectors-pSAT1-nEYFP-C1-AtRBR1 (AGI code, At3g12280) and pSAT1-cEYFP-C1-B-AtCYCD3;1 (AGI code, At4g34160)-were provided by Dr. László Bakó (Umeå Plant Science Centre, Umeå University). The vectors were digested with NaeI and NotI and subsequently introduced into the EcoRV/NotI site of the binary vector pGreenI 0029 [49]. The binary vectors were transformed into A. tumefaciens strain GV3101 (pMP90). The Agrobacterium cells were inoculated in LB media with appropriate antibiotics and grown until the $\mathrm{OD}_{600}$ was above 1.8. The collected cells were washed twice by the MS infiltration medium and re-suspended in $50 \mathrm{~mL}$ of the medium at a final $\mathrm{OD}_{600}$ of 2.0. The same amount of the solutions were mixed and incubated at room temperature for three hours with gentle shaking. Agrobacterium-mediated vacuum infiltration was performed by the method described above. The transformed cuttings were grown on $0.5 \times \mathrm{MS}$ medium $(\mathrm{pH}$ 5.6) with $0.6 \%(\mathrm{w} / \mathrm{v})$ agar and $50 \mu \mathrm{g} / \mathrm{mL}$ Cefotaxime for two days. To visualize nuclei, the leaves were stained with 4,6diamidino-2-phenylindole (DAPI, $5 \mu \mathrm{g} / \mathrm{mL}$, Dojindo, Japan). EYFP fluorescence and DAPI fluorescence were detected using a Leica TCS SPE system with an oilcorrected $63 \mathrm{x}$ objective NA $=1.3$. EYFP and DAPI were excited at $488 \mathrm{~nm}$ and $405 \mathrm{~nm}$ laser, respectively. EYFP and DAPI emission were detected between 510 to $550 \mathrm{~nm}$ and between 430 to $460 \mathrm{~nm}$, respectively.

\section{Luciferase reporter assay}

The promoter region of $P$. tremula $\times P$. tremuloides PttLHY2 was isolated by PCR with following primer sets: forward, 5'-TTAAGCTTTGCCTTCTGCAGATTTTC AG-3'; reverse, 5'-CGGGATCCTAGTGGACCTTAGGC AGCCA-3') [Genbank/EMBL/DDBJ: AB661779]. The PCR products were digested with HindIII and BamHI and subsequently introduced into the HindIII/BamHI site of the binary vector pPZP221-luc ${ }^{+}$[50]. The binary vector was transformed into A. tumefaciens (GV3101 pMP90). Agrobacterium-mediated vacuum infiltration was performed by the same protocol described above. The transformed cuttings were grown on $0.5 \times \mathrm{MS}$ medium ( $\mathrm{pH} 5.6)$ with $2 \%$ sucrose $(\mathrm{w} / \mathrm{v})$ and $0.8 \%(\mathrm{w} / \mathrm{v})$ agar and brought back to standard growth conditions for a day following transformation. Subsequently, shoot tips with additional younger leaves were cut and transplanted on the same medium. The apices were supplemented with $5 \mathrm{mM}$ luciferin in $0.01 \%$ Triton X-100 and placed under $18 \mathrm{~h}$ light $\left(20 \mu \mathrm{mol} \mathrm{m}^{-2} \mathrm{~s}^{-1}\right) / 6 \mathrm{~h}$ dark; $22^{\circ} \mathrm{C} / 22^{\circ} \mathrm{C}$ condition, light provided from red $(660 \mathrm{~nm})$ and blue $(470 \mathrm{~nm})$ light-emitting diodes (LEDs, MD Electronics, UK). Expression levels reflected by emitted photons were monitored using an ORCA-II-ERG 1024 cooled camera (Hamamatsu Photonics, Japan). Image acquisition and light control were driven by WASABI imaging software (Hamamatsu Photonics, Japan). The images were processed using Metamorph image-analysis software (Molecular Devices, USA).

\section{Statistical analysis}

All statistical analyses were performed with $\mathrm{R}$ package version 2.9 [51].

\section{Additional files}

Additional file 1: Figure S1. Permeability of infiltration medium by syringe injection technique. The white circle indicates the syringe contact area. 
Additional file 2: Figure S2. The LUC activity in the shoot tip, folded and unfolded leaves. (A) Bright field image and (B) LUC bioluminescence eight hours after detection.

\section{Abbreviations \\ BiFC: bimolecular fluorescence complementation; C4H: Cinnamic acid 4- hydroxylase; CaMV: Cauliflower mosaic virus; CLSM: Confocal laser scanning microscopy; CYCD3;1: CYCLIN D3;1; GFP: Green fluorescent protein; GT47C: Glycosyltransferase family 47; LHY2: Late elongated hypocotyl 2; LUC: Luciferase; MTP1: Metal-tolerance protein 1; PrxQ: Peroxiredoxin Q: RBR1: Retinoblastoma-related 1.}

\section{Competing interests}

The authors declare that they have no competing interests.

\section{Authors' contributions}

NT conceived of the study and drafted the manuscript. ME participated in planning, coordination and writing of the manuscript. Both authors read and approved the final manuscript.

\section{Acknowledgements}

We gratefully acknowledge financial support. NT received support from the Kempe Foundation. MEE is a VINNMER Marie Curie International Qualification Fellow funded by the Swedish Governmental Agency for Innovation Systems (VINNOVA) and the European Union assisted with grants from Umeå University, the Berzelii Center of Forest Biotechnology, the Swedish Foundation for Strategic Research, and Nils och Dorthi Troëdssons Forskningsfond. We also wish to thank Krisztina Ötvös and Lászlo Báko for providing us with the pSAT1-nEYFP-C1-AtRBR1 and pSAT1-CEYFP-C1-BAtCYCD3;1 constructs.

\section{Author details}

${ }^{1} U$ meå Plant Science Centre, Department of Plant Physiology, Umeå University, SE-901 87, Umeå, Sweden. ${ }^{2}$ Present address: Forest Bio-Research Center, Forestry and Forest Products Research Institute, Hitachi, Ibaraki 319-1301, Japan. ${ }^{3}$ Department of Plant Sciences, University of Cambridge, Cambridge CB2 3EA, UK.

Received: 28 April 2012 Accepted: 20 July 2012

Published: 7 August 2012

\section{References}

1. Tuskan GA, Difazio S, Jansson S, Bohlmann J, Grigoriev I, Hellsten U, Putnam N, Ralph S, Rombauts S, Salamov A, Schein J, Sterck L, Aerts A, Bhalerao RR, Bhalerao RP, Blaudez D, Boerjan W, Brun A, Brunner A, Busov V, Campbell M, Carlson J, Chalot M, Chapman J, Chen GL, Cooper D, Coutinho PM, Couturier J, Covert S, Cronk Q, et al: The genome of black cottonwood, Populus trichocarpa (Torr. \& Gray). Science 2006, 313:1596-1604.

2. Street NR, Tsai CJ: Populus Resources and Bioinformatics. In Genetics and Genomics of Populus. Edited by Jansson S, Bhalerao R, Groover A. New York: Springer Science+Business Media, LLC; 2010:135-152.

3. Klein TM, Fitzpatrick-McElligott S: Particle bombardment: a universal approach for gene transfer to cells and tissues. Curr Opin Biotechnol 1993, 4:583-590.

4. Zhang Y, Su J, Duan S, Ao Y, Dai J, Liu J, Wang P, Li Y, Liu B, Feng D, Wang J, Wang H: A highly efficient rice green tissue protoplast system for transient gene expression and studying light/chloroplast-related processes. Plant Methods 2011, 7:30.

5. Rasco-Gaunt S, Riley A, Barcelo P, Lazzeri PA: Analysis of particle bombardment parameters to optimise DNA delivery into wheat tissues. Plant Cell Rep 1999, 19:118-127.

6. Orzaez D, Mirabel S, Wieland WH, Granell A: Agroinjection of tomato fruits. A tool for rapid functional analysis of transgenes directly in fruit. Plant Physiol 2006, 140:3-11.

7. Bhaskar PB, Venkateshwaran M, Wu L, Ané JM, Jiang J: Agrobacteriummediated transient gene expression and silencing: a rapid tool for functional gene assay in potato. PLoS One 2009, 4:e5812.

8. Chupeau MC, Pautot V, Chupeau Y: Recovery of transgenic trees after electroporation of poplar protoplasts. Transgenic Res 1994, 3:13-19.
9. Confalonieri M, Balestrazzi A, Bisoffi S, Cella R: Factors affecting Agrobacterium tumefaciens-mediated transformation in several black poplar clones. Plant Cell Tissue and Organ Cult 1995, 43:215-222.

10. Qiao J, Ishihara Y, Kuroda H, Sakai F, Sakai H, Komano T: Transient expression of goat growth hormone gene in poplar (Populus alba L.) protoplasts: a quick method for detection of foreign gene expression in mRNA level. Biosci Biotechnol Biochem 1997, 61:1580-1581.

11. Ma C, Strauss SH, Meilan R: Agrobacterium-mediated transformation of the genome-sequenced poplar clone, Nisqually-1 (Populus trichocarpa). Plant Mol Biol Rep 2004, 22:311-312.

12. Nowak K, Luniak N, Meyer S, Schulze J, Mendel RR, Hänsch R: Fluorescent proteins in poplar: a useful tool to study promoter function and protein localization. Plant Biol 2004, 6:65-73.

13. Zhang $C$, Gai $Y$, Zhu Y, Chen $X$, Jiang $X$ : Construction of a bidirectional promoter and its transient expression in Populus tomentosa. Front Forest China 2008, 3:112-116.

14. Schöb H, Kunz C, Meins F Jr: Silencing of transgenes introduced into leaves by agroinfiltration: a simple, rapid method for investigating sequence requirements for gene silencing. Mol Gen Genet 1997, 256:581-585.

15. Marion J, Bach L, Bellec Y, Meyer C, Gissot L, Faure JD: Systematic analysis of protein subcellular localization and interaction using high-throughput transient transformation of Arabidopsis seedlings. Plant J 2008, 56:169-179.

16. Zottini M, Barizza E, Costa A, Formentin E, Ruberti C, Carimi F, Lo Schiavo F: Agroinfiltration of grapevine leaves for fast transient assays of gene expression and for long-term production of stable transformed cells. Plant Cell Rep 2008, 27:845-853.

17. Chen X, Equi R, Baxter H, Berk K, Han J, Agarwal S, Zale J: A highthroughput transient gene expression system for switchgrass (Panicum virgatum L.) seedlings. Biotechnol Biofuels 2010, 3:9.

18. Chiu W, Niwa Y, Zeng W, Hirano T, Kobayashi H, Sheen J: Engineered GFP as a vital reporter in plants. Curr Biol 1996, 6:325-330.

19. Bhat RA, Lahaye $T$, Panstruga $R$ : The visible touch: in planta visualization of protein-protein interactions by fluorophore-based methods. Plant Methods 2006, 2:12.

20. Millar AJ, Carre IA, Strayer CA, Chua NH, Kay SA: Circadian clock mutants in Arabidopsis identified by luciferase imaging. Science 1995, 267:1161-1163.

21. Miwa K, Serikawa M, Suzuki S, Kondo T, Oyama T: Conserved expression profiles of circadian clock-related genes in two Lemna species showing long-day and short-day photoperiodic flowering responses. Plant Cell Physiol 2006, 47:601-612.

22. Kim J, Somers DE: Rapid assessment of gene function in the circadian clock using artificial microRNA in Arabidopsis mesophyll protoplasts. Plant Physiol 2010, 154:611-621.

23. Mahmoudian M, Yücel M, Öktem HA: Transformation of lentil (Lens culinaris M.) cotyledonary nodes by vacuum infiltration of Agrobacterium tumefaciens. Plant Mol Biol Rep 2002, 20:251-257.

24. de Oliveira ML, Febres VJ, Costa MG, Moore GA, Otoni WC: High-efficiency Agrobacterium-mediated transformation of citrus via sonication and vacuum infiltration. Plant Cell Rep 2009, 28:387-395.

25. Manavella PA, Chan RL: Transient transformation of sunflower leaf discs via an Agrobacterium-mediated method: applications for gene expression and silencing studies. Nat Protoc 2009, 4:1699-1707.

26. Li JF, Park E, von Arnim AG, Nebenführ A: The FAST technique: a simplified Agrobacterium-based transformation method for transient gene expression analysis in seedlings of Arabidopsis and other plant species. Plant Methods 2009, 5:6.

27. Nilsson O, Aldén T, Sitbon F, Little CHA, Chalupa V, Sandberg G, Olsson O: Spatial pattern of cauliflower mosaic virus $35 \mathrm{~S}$ promoter-luciferase expression in transgenic hybrid aspen trees monitored by enzymatic assay and non-destructive imaging. Transgenic Res 1992, 1:209-220.

28. Blaudez D, Kohler A, Martin F, Sanders D, Chalot M: Poplar metal tolerance protein 1 confers zinc tolerance and is an oligomeric vacuolar zinc transporter with an essential leucine zipper motif. Plant Cell 2003, 15:2911-2928.

29. Rouhier N, Gelhaye E, Gualberto JM, Jordy MN, De Fay E, Hirasawa M, Duplessis S, Lemaire SD, Frey P, Martin F, Manieri W, Knaff DB, Jacquot JP: Poplar peroxiredoxin Q. A thioredoxin-linked chloroplast antioxidant functional in pathogen defense. Plant Physiol 2004, 134:1027-1038.

30. Sasaki K, Ohara K, Yazaki K: Gene expression and characterization of isoprene synthase from Populus alba. FEBS Lett 2005, 579:2514-2518. 
31. Rinne PL, Welling A, Vahala J, Ripel L, Ruonala R, Kangasjärvi J, van der Schoot C: Chilling of dormant buds hyperinduces FLOWERING LOCUS T and recruits GA-inducible 1,3- $\beta$-glucanases to reopen signal conduits and release dormancy in Populus. Plant Cell 2011, 23:130-146.

32. Ro DK, Mah N, Ellis BE, Douglas CJ: Functional characterization and subcellular localization of poplar (Populus trichocarpa $\times$ Populus deltoides) cinnamate 4-hydroxylase. Plant Physiol 2001, 126:317-329.

33. Zhou GK, Zhong R, Richardson EA, Morrison WHIII, Nairn CJ, Wood-Jones A, Ye ZH: The poplar glycosyltransferase GT47C is functionally conserved with Arabidopsis Fragile Fiber8. Plant Cell Physiol 2006, 47:1229-1240.

34. Achnine L, Blancaflor EB, Rasmussen S, Dixon RA: Colocalization of L-phenylalanine ammonia-lyase and cinnamate 4-hydroxylase for metabolic channeling in phenylpropanoid biosynthesis. Plant Cell 2004, 16:3098-3109

35. Zhong R, Peña MJ, Zhou GK, Nairn CJ, Wood-Jones A, Richardson EA Morrison WHIII, Darvill AG, York WS, Ye ZH: Arabidopsis fragile fiber8, which encodes a putative glucuronyltransferase, is essential for normal secondary wall synthesis. Plant Cell 2005, 17:3390-3408.

36. Lee $\mathrm{C}$, Teng Q, Huang W, Zhong R, Ye ZH: The Arabidopsis family GT43 glycosyltransferases form two functionally nonredundant groups essential for the elongation of glucuronoxylan backbone. Plant Physiol 2010, 153:526-541.

37. Gehl C, Waadt R, Kudla J, Mendel RR, Hänsch R: New GATEWAY vectors for high throughput analyses of protein-protein interactions by bimolecular fluorescence complementation. Mol Plant 2009, 2:1051-1058.

38. Boruc J, Van den Daele H, Hollunder J, Rombauts S, Mylle E, Hilson P, Inzé D, De Veylder L, Russinova E: Functional modules in the Arabidopsis core cell cycle binary protein-protein interaction network. Plant Cell 2010, 22:1264-1280

39. Pruneda-Paz $J$, Kay SA: An expanding universe of circadian networks in higher plants. Trends Plant Sci 2010, 15:259-265.

40. Takata N, Saito S, Saito CT, Nanjo T, Shinohara K, Uemura M: Molecular phylogeny and expression of poplar circadian clock genes, LHY1 and LHY2. New Phytol 2009, 181:808-819.

41. Ibáñez C, Kozarewa I, Johansson M, Ögren E, Rohde A, Eriksson ME: Circadian clock components regulate entry and affect exit of seasonal dormancy as well as winter hardiness in Populus trees. Plant Physiol 2010, 153:1823-1833.

42. Niwa Y, Hirano T, Yoshimoto K, Shimizu M, Kobayashi H: Non-invasive quantitative detection and applications of non-toxic, S65T-type green fluorescent protein in living plants. Plant J 1999, 18:455-463.

43. Yamazaki T, Kawamura Y, Minami A, Uemura M: Calcium-dependent freezing tolerance in Arabidopsis involves membrane resealing via synaptotagmin SYT1. Plant Cell 2008, 20:3389-3404.

44. Sambrook J: Russell DW: Molecular cloning: a laboratory manual. 3rd edition New York: Cold Spring Harbor Laboratory Press; 2001

45. Hajdukiewicz P, Svab Z, Maliga P: The small, versatile pPZP family of Agrobacterium binary vectors for plant transformation. Plant Mol Biol 1994, 25:989-994.

46. Sterky F, Bhalerao RR, Unneberg P, Segerman B, Nilsson P, Brunner AM, Charbonnel-Campaa L, Lindvall JJ, Tandre K, Strauss SH, Sundberg B, Gustafsson P, Uhlén M, Bhalerao RP, Nilsson O, Sandberg G, Karlsson J, Lundeberg J, Jansson S: A Populus EST resource for plant functional genomics. Proc Natl Acad Sci USA 2004, 101:13951-13956.

47. Koncz C, Schell J: The promoter of $\mathrm{T}_{L}$-DNA gene 5 controls the tissuespecific expression of chimaeric genes carried by a novel type of Agrobacterium binary vector. Mol Gen Genet 1986, 204:383-396.

48. ImageJ 1.44, http://rsb.info.nih.gov/ij/.

49. Hellens RP, Edwards EA, Leyland NR, Bean S, Mullineaux PM: pGreen: a versatile and flexible binary Ti vector for Agrobacterium-mediated plant transformation. Plant Mol Biol 2000, 42:819-832.

50. McWatters HG, Kolmos E, Hall A, Doyle MR, Amasino RM, Gyula P, Nagy F, Millar AJ, Davis SJ: ELF4 is required for oscillatory properties of the circadian clock. Plant Physiol 2007, 144:391-401.

51. R Development Core Team: $R$ : A language and environment for statistical computing. Vienna, Austria: R Foundation for Statistical Computing; 2009.

doi:10.1186/1746-4811-8-30

Cite this article as: Takata and Eriksson: A simple and efficient transient transformation for hybrid aspen (Populus tremula $\times$ P. tremuloides). Plant Methods 2012 8:30.

\section{Submit your next manuscript to BioMed Central and take full advantage of:}

- Convenient online submission

- Thorough peer review

- No space constraints or color figure charges

- Immediate publication on acceptance

- Inclusion in PubMed, CAS, Scopus and Google Scholar

- Research which is freely available for redistribution 